\title{
Increasing the Adoption of Canadian Retail Businesses' Websites: Canadian Young Generation Consumers' Enticement
}

\author{
Allen Lim Chong Guan', Goi Chai Lee ${ }^{2}$, Peter Dell ${ }^{3}$ \\ ${ }^{1}$ East Stroudsburg University, USA \\ ${ }^{2,3}$ Curtin University, AUSTRALIA
}

\begin{abstract}
This research contributes significantly to academic and practitioner knowledge in the areas of young generation customers' enticement for expanding the adoption of small companies and internet commerce. This is the first time that a study has been done especially on the behavioural usage of Canadian Young consumers' websites by Canadian retail businesses. The purpose of this study is to gain a better understanding of how the Canadian Young Generation engages with retail firms' websites. The research model for this study is an adaptation of the UTAUT2 paradigm. It reaffirms the literature review's usage of the modified UTAUT2 model to describe this research. This research aims to fill a need in the existing knowledge about the Canadian Young Generation's use of retail firms' websites. It is critical that additional steps to protect security and privacy, as well as to create trust, be implemented to improve Young Generation confidence in the retail websites of small Canadian firms. Internet costs remain high in Canada, and it is proposed that the Canadian federal government provide additional licenses to Internet Service Providers (ISPs) in order to increase competition among ISPs and therefore decrease Internet charges.
\end{abstract}

Key Words: Retail Business, Adoption of Retail Websites, Young Generation, Consumers' Enticement

\section{INTRODUCTION}

It has been a success for Canadian small businesses to improve the quality of life for Canadians through their products. The development and progress of Canadian small enterprises, on the other hand, may use some work. Over the last year, small firms in Canada have employed 8.2 million people, or $70.5 \%$ of the overall private sector, making a substantial contribution to the country's growth and stability (Innovation, Science and Economic Development Canada, 2016). It was estimated that 1.14 million small enterprises (1 to 99 employees) accounted for $97.90 \%$ of all Canadian employer firms in December 2015. (Innovation, Science and Economic Development Canada, 2016). However, the success of Canadian small enterprises is also influenced by the country's economic, political, and social climates (Ensign, 2008). With the establishment of the North American Free Trade Area (NAFTA) in 1992, strong links were created between the two countries.

A little more than $30 \%$ of Canada's GDP was generated by small and medium-sized enterprises (GDP). Five million Canadians were employed by small enterprises in 2010. Consumer spending growth of 1 percent is associated with a $0.7 \%$ increase in small business 
revenue (CIBC World Markets, 2003). As a result, small businesses play a crucial role in creating jobs for Canadians.

For the year 2012, the value of online retail sales in Canada increased by C $\$ 0.7$ billion, according to Statistics Canada (Statistics Canada, 2014). Customers buying more frequently and in larger quantities on the internet contributed to the growth (Manojkumar et al., 2021; Sharma et al., 2021; Donepudi et al., 2020a). However, according to Yousefi and Tang (2012)'s empirical research, security was remained the most pressing issue when it came to Internet use. Concerns regarding credit card transactions and privacy issues may go away, though, if third-party payment verifiers like PayPal are included.

The young generation likes to deal with small businesses because they believe that giant corporations are reluctant to adapt to shifting trends and are not in direct contact with their consumers' demands and desires (Garner, 2010). As the most educated generation to date in Canada, Generation Y (Redmond, 2014) demands plain and easy communication while also leading an active and healthy lifestyle (Jones, 2011). They also value having a healthy worklife balance (McDonald and Hite, 2008). This generation aspires to a high standard of living, surrounded by loved ones, friends, and the people in their neighborhood and beyond (Marilee, 2011). However, because they are constantly exposed to a changing world, adolescents may easily lose interest in a subject (Canadian Association of Marketing Professionals, 2014).

With their growing careers, families, and homes, Canadian young people are becoming increasingly prosperous (Canada Post, 2017). The younger generation is Canada's largest living generation, and as they develop in their occupations, they become better-off (Guffey, Rhodes and Rogin, 2010). Due to the high growth potential of this sector, it is an important one for consumers that is underutilized right now. Shoppers' behavioral intentions must be better understood by merchants if they are to grasp this market.

Canadian small retailers are faced with competition from large US e-commerce subsidiaries such as Amazon.com and Amazon.ca, Apple, eBay.ca, Costco.ca, and Walmart.ca that dominate e-commerce in Canada (Shaw, 2017). These retailers generated sales of $C \$ 3.5$ billion, $\mathrm{C} \$ 1.6$ billion, $\mathrm{C} \$ 1.5$ billion, $\mathrm{C} \$ 771$ million, and $\mathrm{C} \$ 605$ million, respectively, in 2016. The top 22 retailers in Canada generated two-thirds of the e-commerce of C $\$ 18$ billion (Shaw, 2017). There can be structural differences between large and small retailers in terms of pricing, product variety, operational costs, promotional activities, manpower, reputation, financial support, supplier relationship, distance, customer relationship, sales channels, payment modes, customer service, and training (Toma, 2014).

However, very little study has been conducted on the factors that contribute to the success of internet retailing in general (Donepudi et al., 2020b; Rahman et al., 2020; Khan et al., 2020; Donepudi et al., 2020c). At the moment, no academic study focusing on the behavioral usage of Canadian retail organizations' websites by the younger generation is being conducted, and the underlying factors are unknown. As such, the objective of this research is to close this gap by examining Canadian Young Generations' online behavioral intention and behavioral motivation, so contributing to the current body of knowledge. By gaining a deeper grasp of these individuals' behavioral intentions, Canadian small business retailers can improve their long-term engagement and service. 


\section{Methodology}

\section{Research Question}

How can Canadian Generation Y consumers be enticed to increase the adoption of Canadian small business retail websites?

Data was collected from personal interviews to answer Research Question. This question is based on how Canadian Generation Y consumers can be enticed to increase the adoption of Canadian small business retail websites.

\section{Research Hypothesis}

Canadian Generation Y consumers can be enticed to increase the adoption of Canadian small business retail websites.

Based on the literature review, security and privacy, and trust factors have been added as an extension of the UTAUT2 model for this study. The UTAUT2 model is based on reflective indicators. This is a reflective model that is based on hypothetical assumptions and deduction (Baumann, Elliott and Hamin, 2011). Most SEM studies are based on reflective models (Baumann, Elliott and Hamin, 2011). Reflective indicators include Confirmatory Factor Analysis (CFA) and internal consistency reliability (Cronbach's Alpha) (Diamantopoulos, 1999).

\section{Security and Privacy on Retall Websites}

The security and privacy factor for UTAUT2 model was found to be insignificant. This section focuses on gathering information on what Canadian Generation Y consumers think of the security and privacy on retail websites.

According to a research conducted by Alharbi, Zyngier and Hodkinson (2013), most users depend on the organisational reputation as a cue to judge the degree of online privacy and protection. The users check the rating of security and privacy of the websites before buying online. One of the ways to increase trust is for online retailers to provide product information and secure third-party product assurances (Dimoka, Hong and Pavlou, 2012; Ponte, CarvajalTrujillo and Escobar-Rodriguez, 2015). Small retailers and unknown online retailers could benefit commercially by getting third-party certifications as these certifications make economic sense for building initial trust with prospective customers (Kim and Kim, 2011). A minimum level of security should be in place for small businesses where there are concerns relating to physical security, access control, presence of malware software, patching updates, firewalls, incident management, periodic log, data backup and recovery, training of personnel, and responsibility delegation (Clarke, 2013).

The probabilistic statistic for attesting a factor such as privacy and security is based on a significance value of 0.05 . However, as a researcher, it cannot identify the various degrees of acceptance of non-significance influence of security and privacy concerns. A qualitative personal interview enables the researcher to better understand, with greater insight, the levels of mitigation for the security and privacy risks for Canadian small business retail websites by the Canadian Generation Y consumers.

The Six C's model (Glaser, 1978) has been used in the diagram on Figure 1 below. The diagram demonstrates why security and privacy do not prevent Canadian Generation Y consumers 
from visiting and shopping at Canadian small business retail websites. The factors in this section are an extension of the UTAUT2 model.

The context is focused on trust in assessing why security and privacy are not a concern for Canadian Generation Y consumers. The causes include the reputation of the retail websites, certification, and security and privacy policy. The condition is based on the reputation of the retail websites, certification, and security and privacy policy to provide the support for Canadian Generation Y consumers to feel unconcerned about security and privacy on the Canadian small business retail websites. The category is called the unimportance of security and privacy concerns for Canadian small business retail websites. The consequences are the reputation of the retail websites, certification, and security and privacy policy that result in Canadian Generation Y consumers being unconcerned with the security and privacy for Canadian small business retail websites. Covariance refers to the strategies to mitigate the causes of security and privacy concerns for Canadian small business retail websites. Lastly, contingencies refer to strategies for the causes to mitigate the security and privacy risks for Canadian small business retail websites.

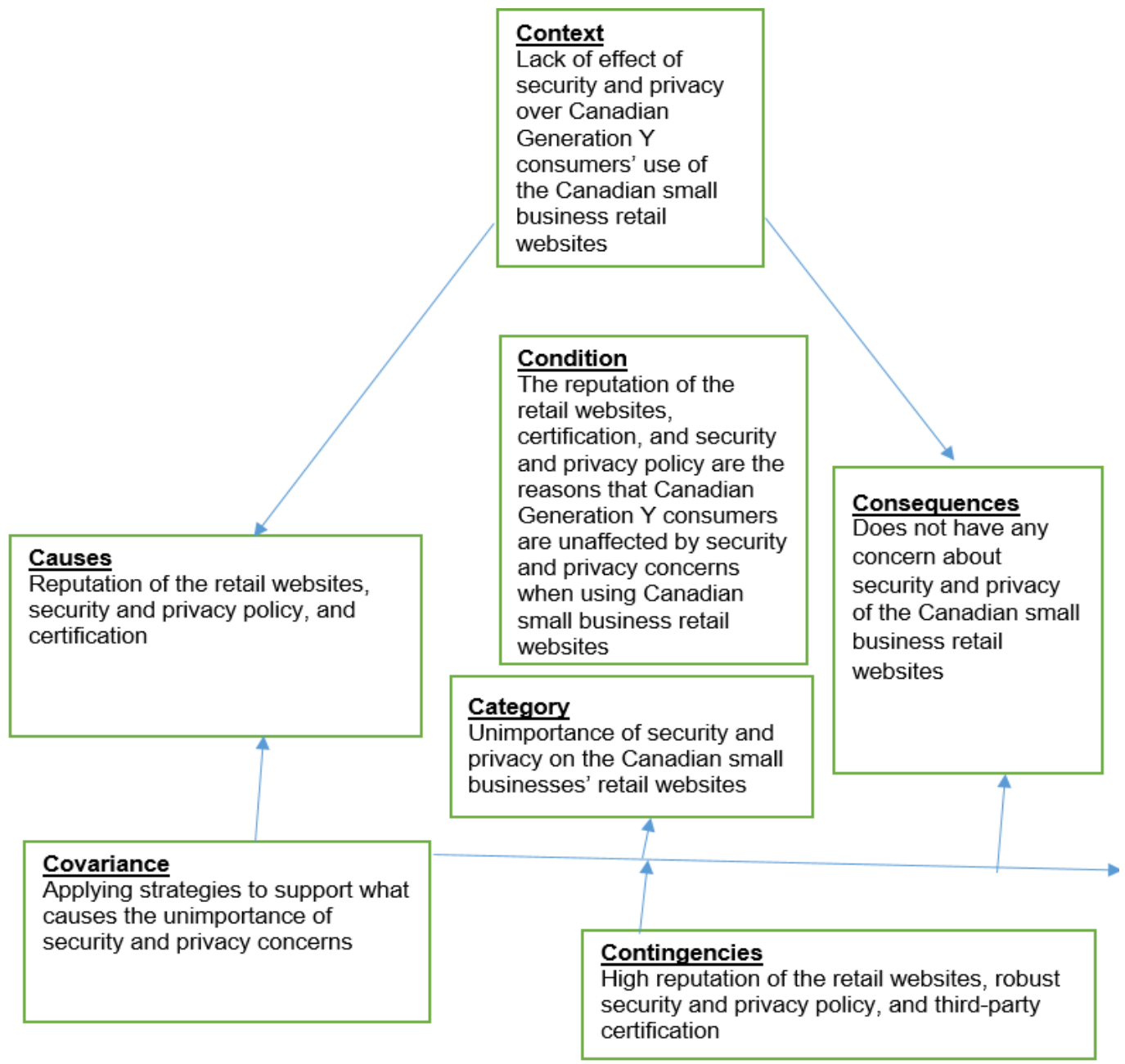

Figure 1: Security and Privacy on Retail Websites 


\section{Context}

The context is based on the lack of effect of security and privacy over Canadian Generation $Y$ consumers' use of the Canadian small business retail websites.

\section{Condition}

The reputation of the retail websites, certification, and security and privacy policy are the reasons that Canadian Generation $\mathrm{Y}$ consumers are unaffected by security and privacy concerns when using Canadian small business retail websites.

\section{Causes}

The causes are the reputation of the retail websites, security and privacy policy, and certification.

Reputation of Retail Websites: The reputation of retail websites can help mitigate the security and privacy risks of retail websites. In the context of this section, the discussion of the reputation of the retail websites focuses on security and privacy through the perspective of the interviewees' responses. A10 claimed, "I do not have problems with security and privacy on retail websites, but it is best to do research on those websites." By carrying out research, consumers would have better insights and understanding about the retail websites that they would use or engage. A10, therefore, mitigates security and privacy concerns by carrying out research about the specific retail website.

Security and Privacy Policy: Having a security and privacy policy can offset the security and privacy risks of retail websites. In the context of this research, the researcher uses the term "security and privacy policy" to be more specific, although it is common for retail websites to just classify it as "privacy policy". Security and privacy are intertwined as privacy concerns are a part of security concerns. Where retail websites have a clear security and privacy policy, consumers are more convinced about them. At the same time, retailers cannot say that they are ignorant about the law. A security and privacy policy is a legally binding document and although generally, a privacy policy appears as part of the terms and conditions of a security policy, it is nevertheless a separate factor.

Certification: A third party can facilitate the online interaction between two parties. A5 thinks that "I feel retail websites are safer than the Internet as they have third-party certifications". Having a third-party certification would provide traceability for any transaction. If there is a cookie or related feature that has been activated, it must be spelt out. Some of the major third-party certification providers are Web Trust, VeriSign, Truste, and BBBOnline.

\section{Category}

This category focuses on the unimportance of security and privacy for use of Canadian small business retail websites.

\section{Consequences}

The consequences are Canadian Generation Y consumers not being concerned about security and privacy to use the Canadian small business retail websites.

\section{Covariance}

Covariance is based on the strategies to mitigate the unimportance of security and privacy concerns of Canadian Generation Y consumers for Canadian small business retail websites. 


\section{Contingencies}

The contingencies are the high reputation of the retail websites, a robust security and privacy policy, and third-party certification.

\section{INFORMATION AND COMMUNICATION TECHNOLOGIES SUPPORT IN CANADA}

This section focuses on an understanding of the information and communication technologyrelated infrastructural support in Canada. This support comes in the form of computers software, Internet infrastructure, and other hardware. There appears to be some confidence expressed in Canadian infrastructural support.

It can be said that overall, the technological support and infrastructure in Canada is good and will continue to improve. Recently, the government of Canada has invested C $\$ 105$ million in CANARIE for the period of 2015-2020 (CANARIE, 2015). CANARIE is a non-profit organisation that has designed and established a digital infrastructure and spearheaded the establishment of Canada's research and innovation for different communities of interest.

The Six C's model (Glaser, 1978), based on the data, has been used in Figure 2 below. The diagram shows the information and communication technologies support in Canada.

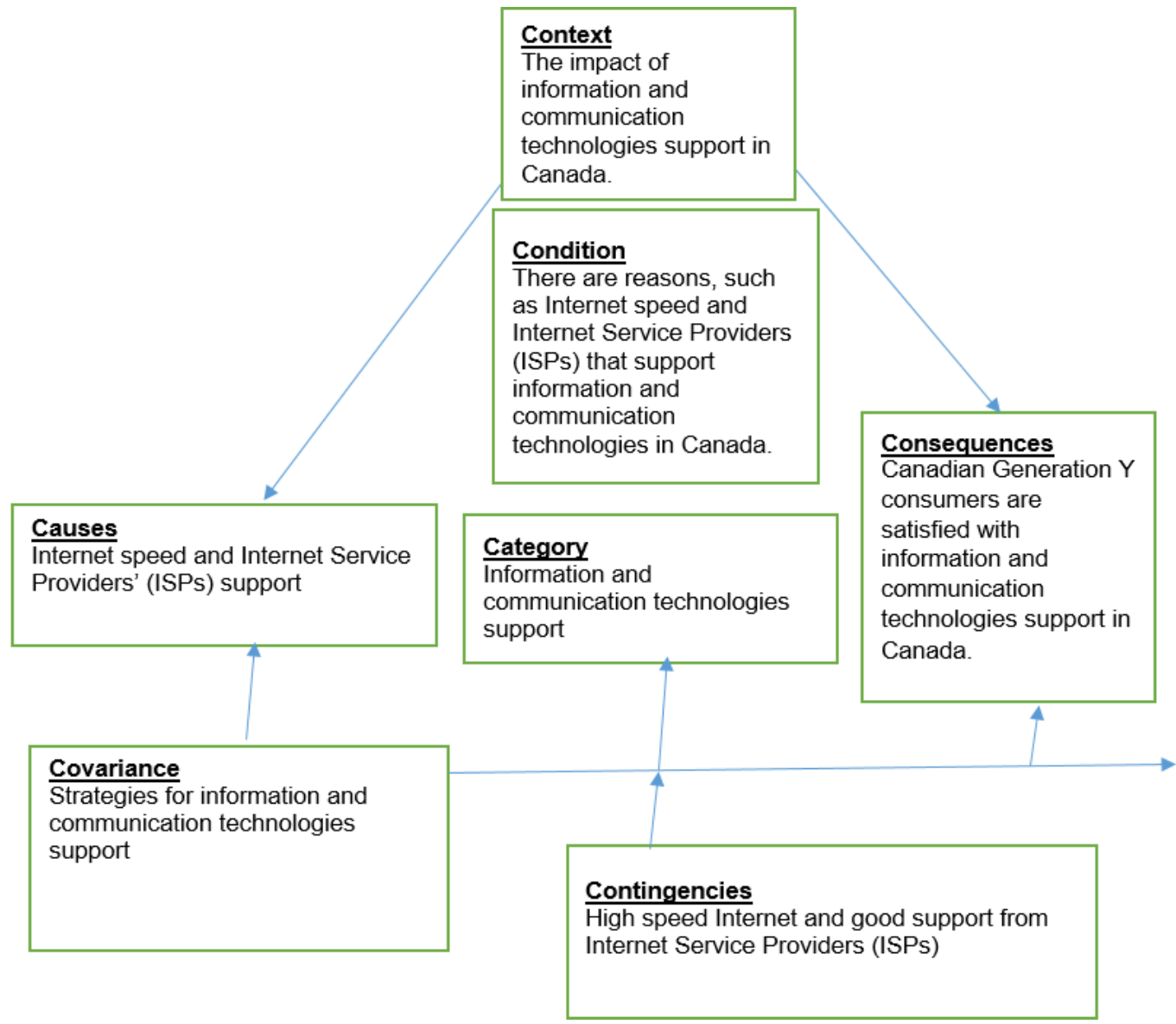

Figure 2: Information and Communication Technologies Support 
The model focuses on the impact of information and communication technologies support in Canada. The conditions that support information and communication technologies are Internet speed and Internet Service Providers' (ISPs) support. The category is called information and communication technologies. The causes are Internet speed and Internet Service Providers (ISPs). The consequences are, generally, Canadian Generation $Y$ consumers are satisfied with information and communication technologies support in Canada. Covariance is the expression of what strategies are available to provide information and communication technologies support. Contingencies are high speed Internet and good support from Internet Service Providers (ISPs).

\section{Context}

This context is based on the impact of information and communication technologies support in Canada.

\section{Condition}

There are conditions, such as Internet speed and Internet Service Providers' (ISPs), that support information and communication technologies in Canada.

\section{Causes}

The causes are based on the Internet speed and the Internet Service Providers' (ISPs) support.

Internet Speed: The interviewees are generally satisfied with the Internet speed as one of the Facilitating Conditions. According to A7, "In Canada, the support for information and communications is good as it is fast and easy to access the Internet." According to A3, "Generally, access to the Internet is good without many interruptions, except for limited bandwidth usage at times". The Internet downtime in Canada is minimal and the Internet access speed is one of the fastest in the world.

Internet Service Providers' (ISPs) Support: The term Internet Service Providers (ISPs) includes the Internet and computer support for Internet access. Generally, in Canada, the Internet access downtime is negligible that serves as a one of the several positive "Facilitating Conditions." Nevertheless, there is a need to maintain a high level of customer service that is not exclusively focused on technical matters but also on the administrative ones that must be resolved in due time. A14 thinks that "The information and communication technologies support is one of the best in the world." A28 adds that, "Technological support in general is excellent to cover a country that has such a diverse geographical landscape." This can be considered a great achievement for Canada to support such a good infrastructure despite its large size.

\section{Category}

The category is called information and communication technologies support.

\section{Consequences}

Canadian Generation Y consumers are generally satisfied with the information and communication technologies support in Canada.

\section{Covariance}

Covariance refers to strategies for information and communication technologies support.

\section{Contingencies}

Contingencies are high speed Internet and good support from Internet Service Providers (ISPs). 


\section{LAWS GOVERNING INTERNET COMMERCE}

This section focuses on collecting information from Canadian Generation Y consumers on their opinions about the governing laws of Internet commerce. The laws that govern Internet commerce can be deemed to be a pillar to create Internet commercial growth.

Many Canadian Generation Y consumers are not too familiar with laws governing the Internet and Electronic commerce. The Canadian Federal government has acted to promote Internet commerce by supporting new laws to increase online security and privacy.

On 18th June 2015, the Digital Privacy Act was sanctioned as a law by the Canadian government (Government of Canada, 2015). Under this act, companies are required to inform consumers when their personal information has been lost or stolen and a failure to do so may lead to fines up to $C \$ 100,000$. Companies that collect online personal information must communicate in clear and simple language their purpose for doing so and the related consequences. Personal information can only be disclosed for public interest and to carry out business activities.

The Privacy Commissioner of Canada has also been given additional powers and flexibility to carry out their enforcement. As of 15th January 2015, new Canadian anti-spam legislation prohibits any business engagement from installing software onto another person' computer device without prior approval from the user (Government of Canada, 2015a).

\section{Canadian Government's Promotion of InTERnet Commerce}

This section focuses on the Canadian government's promotion of Internet commerce.

The interviewees claim that not much is done by the Canadian Federal Government and the provincial and territorial governments to promote Internet commerce. In contrast, according to Ed Fast, Canadian Minister of International Trade (Government of Canada, 2015b), "In today's modern economy, it is becoming increasingly important for companies to include e-commerce in their business plans. Today's Go Global workshop provides many opportunities to discuss how small and medium-sized enterprises can take advantage of the Internet and digital technologies to compete both at home and in international markets. Our government will continue to be a strong partner in their journey to expand their markets and create opportunities here in Canada." Therefore, the government may need to advertise its work in this area more and reach out to small retailers with information and support.

\section{Retall Websites' Features}

This section focuses on the Canadian Generation Y consumers' preference for certain retail websites features. These features can enhance the aesthetics of the websites, highlight certain important information and promotions, and provide an improved navigability.

This section focuses on retail website features based on the user interface rather than marketing activities. Canadian Generation Y consumers want to see retail websites that are simple with large graphics and banners, differing colours, conformity, and an easy checkout. The website design should include themes, product information, and previous customers' feedback. From the perspective of the users, designing a simple appealing design based on suitable graphics and categorisation may entice users to visit the website (Rosen and Purinton, 2004). A good web design should not be overloaded with information but should offer ease of accessibility. A simple design enables faster loading where the users will not need to wait 
for more than 10 seconds to be directed to the website. Nowadays, as technology improves, there are many automated tools for website development. With better user interaction, simplicity in design can be achieved. Interactive features on a website enable users to immerse themselves into the online world and explore it (Noort, Voorveld and Reijmersdal, 2012). However, there should be flexibility and balance when designing web content, which also accommodates user diversity (Rosen and Purinton, 2004).

For webpages to remain consistent, the concept of block cluster should be applied. A block cluster is defined as a group technique where having the same information on a website creates consistency among the same elements and groupings while creating a contrast when they are different. Hyperlinks that are effectively linked to webpages on websites enable users to engage in fast and easy searches (Fang, Hu, Chau, Hu, Yang and Sheng, 2012).

For Generation Y consumers, there is a preference to see and use high graphic design and side-panel advertisements as compared to pop-ups advertisements (Smith, 2011). Generation $\mathrm{Y}$ consumers like to see content with large images, limited texts, search bar, and images of celebrities (Djamasbi, Siegel and Tullis, 2010). For an online banner to be effective, the time of exposure should be long enough to achieve a high visual attention (Tangmanee, 2013). When a user clicks on a banner, the advertised webpage would be shown, and banners could be customised based on each user (Turban, King, Lee, Liang and Turban, 2015).

Figure 3 below shows the Six C's Model (Glaser, 1978) on Retail Websites Features based on the data. The features focus on websites' interfaces rather than all marketing activities. The data collected from interviewees provides consumer interpretations of why websites are designed in a certain manner. This may not fully explain website design from the perspective of website designers, such as design based on uploading and downloading speeds, the best format to use based on data size reduction, and other technical aspects. The factors discussed below are an extension of Effort Expectancy factor of UTAUT2.

The context is based on the Canadian small business retail website features. The condition is based on layout, colours, word style, themes, and interaction that can appeal to Canadian Generation $\mathrm{Y}$ consumers, and the category is called Canadian retail websites features. Consequences refer to the retail website features that attract Canadian Generation $Y$ consumers to their retail websites. Covariance refers to the strategies that influence the retail websites features. Contingencies are based on a simple layout, contrasting colours, bright colours, catchy words, simple background, grid layout, theme, standardisation, visual, videos, categorisation, positive interaction, and stylish design.

\section{Context}

The context is based on Canadian small business retail websites' features.

\section{Condition}

The condition is based on layout, colours, word style, themes, and interaction on retail websites that attract Canadian Generation Y consumers.

\section{Causes}

The causes are layout, colours, word style, themes, and interaction.

\section{Category}

The category is called Canadian retail websites' features. 


\section{Consequences}

Canadian Generation Y consumers are attracted to layout, colours, word style, themes, and interaction of retail websites.

\section{Covariance}

Covariance refers to strategies to include certain features of retail websites.

\section{Contingencies}

The contingencies are a simple layout, contrasting colours, bright colours, catchy words, simple background, grid layout, theme, standardisation, visual, videos, categorisation, positive interaction, and stylish design.

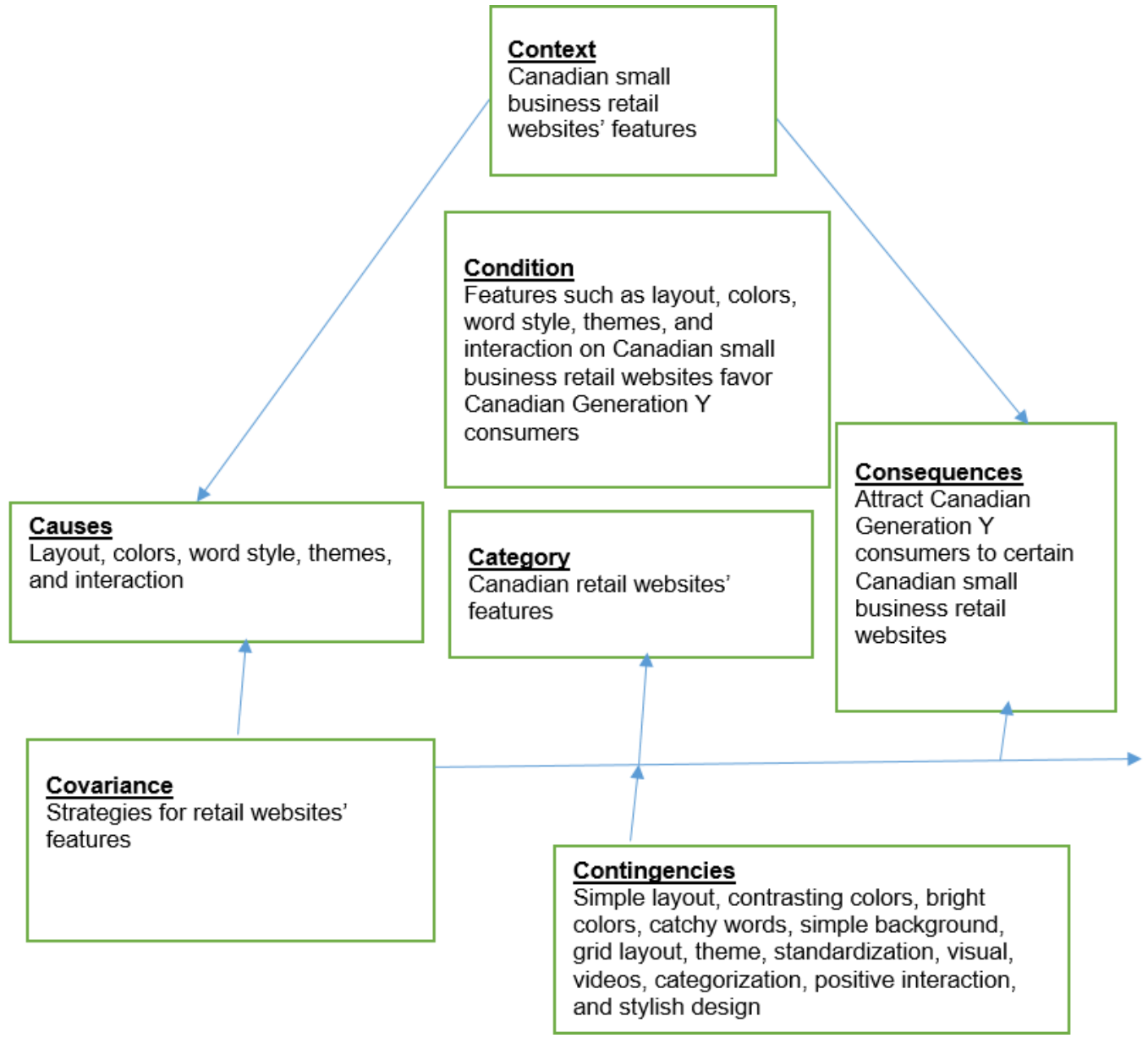

Figure 3: Retail Websites' Features

\section{AdVERTISEMENTS FOR RETAIL WEBSites}

This section focuses on gathering information from Canadian Generation $Y$ consumers about their opinions on advertisements for retail websites. Advertisements can help create awareness about the products and services and about the retail websites as well. 
Retailers should be careful not to overwhelm customers and prospective customers with advertisements as they may prove to be counterproductive. Advertisements that are easy to ignore or are of interest are considered less annoying as compared to those that are difficult to ignore or less interesting. Intrusive kinds of advertising are the most annoying (Lightner and Zeng, 2011) and pop-up advertisements are considered to be one of the most annoying features on the Internet (Turban et al., 2015). Pop-ups can be difficult to close, but most browsers offer an option to prevent pop-up advertisements.

Customers are expecting to see valuable content in the form of something that is meaningful, educational, and fun (Jefferson and Tanton, 2013). According to Jonathan Mildenhall, Coca Cola Vice-President of Global Advertising Strategy and Creative Excellence (Jefferson and Tanton, 2013, p. 27): "All advertisers need a lot more content so that they can keep the engagement with consumers fresh and relevant, because of 24/7 connectivity. If you're going to be successful around the world, you have to have fat and fertile ideas on the core."

There is a substantial advantage in using brands as keywords in search engines, as by collecting data from online transactions, companies can track online interactions, such as the advertisements users clicked on, terms users used for search, and the actions that resulted in the closing of a sale (Jansen, Sobel and Zhang, 2011). The mechanics behind a game is based on rewarding individuals with completed specific tasks (Swan, 2012).

Email advertisement is considered to be a cheap way to reach many subscribers (Turban et al., 2015). As most Internet users view and send emails every day, advertisements could be received by customers at a faster pace. Customers tend to respond to emails that offer special offers and discounts. The email medium is interactive and can be used to advertise and provide customer service. An email can also act as a banner as it can be linked to any website. However, email advertisements can be blocked when a user deems them to be spam.

Another form of online advertising would be Uniform Resource Locator (URL) advertising. Most search engine companies would allow businesses to submit their URLs without any charge and Internet users would be able to search for subject matters using search engines (Turban et al., 2015). Nevertheless, when using search engines, a specific URL may not be shown on the top of the display list.

\section{Customer Loyalty Programs}

This section considers the opinion of Canadian Generation Y consumer on customer loyalty programmes. Customer loyalty programmes can help to retain customers and increase customer purchases and have received considerable positive reinforcement from those interviewed in this study.

It is important for retailers to retain customers, which can be done when retailers have good customer loyalty programmes. The objective of a customer loyalty programme is to retain present customers and increase profits (Dowling and Uncles, 1997). By having an online loyalty programme, retailers could take advantage by collecting customer data (Shin and Sudhir, 2010). However, there are signs that customer loyalty programmes are becoming saturated and their benefits seem to be reduced (Dorotic, Bijmolt and Verhoef, 2012). However, switching costs could be used as a strategy to maintain customer loyalty (Blut, Beatty, Evanschitzky and Brock, 2014). The internal switching costs would risk the search and learning experience, depending on each customer's expertise. 


\section{Trust Influence on CanAdian Generation Y Consumers' Use OF CANAdian SMALL BUSINESS RETAIL WEBSITES}

This section makes inquiries into why trust does not influence Canadian Generation Y consumers' use of Canadian small business retail websites. Trust can vary from individual to individual based on perceptions, experiences, and expectations. Without a certain level of trust, it is difficult for Canadian Generation consumers to purchase online. These uncertainties can come in the form of security and privacy breaches on personal information, slow access, unscrupulous pricing, and false advertising.

Figure 4 below shows the Six C's model (Glaser, 1978) on trust on retail websites based on the data. The data collected is the extension of the Trust factor of the UTAUT2 model.

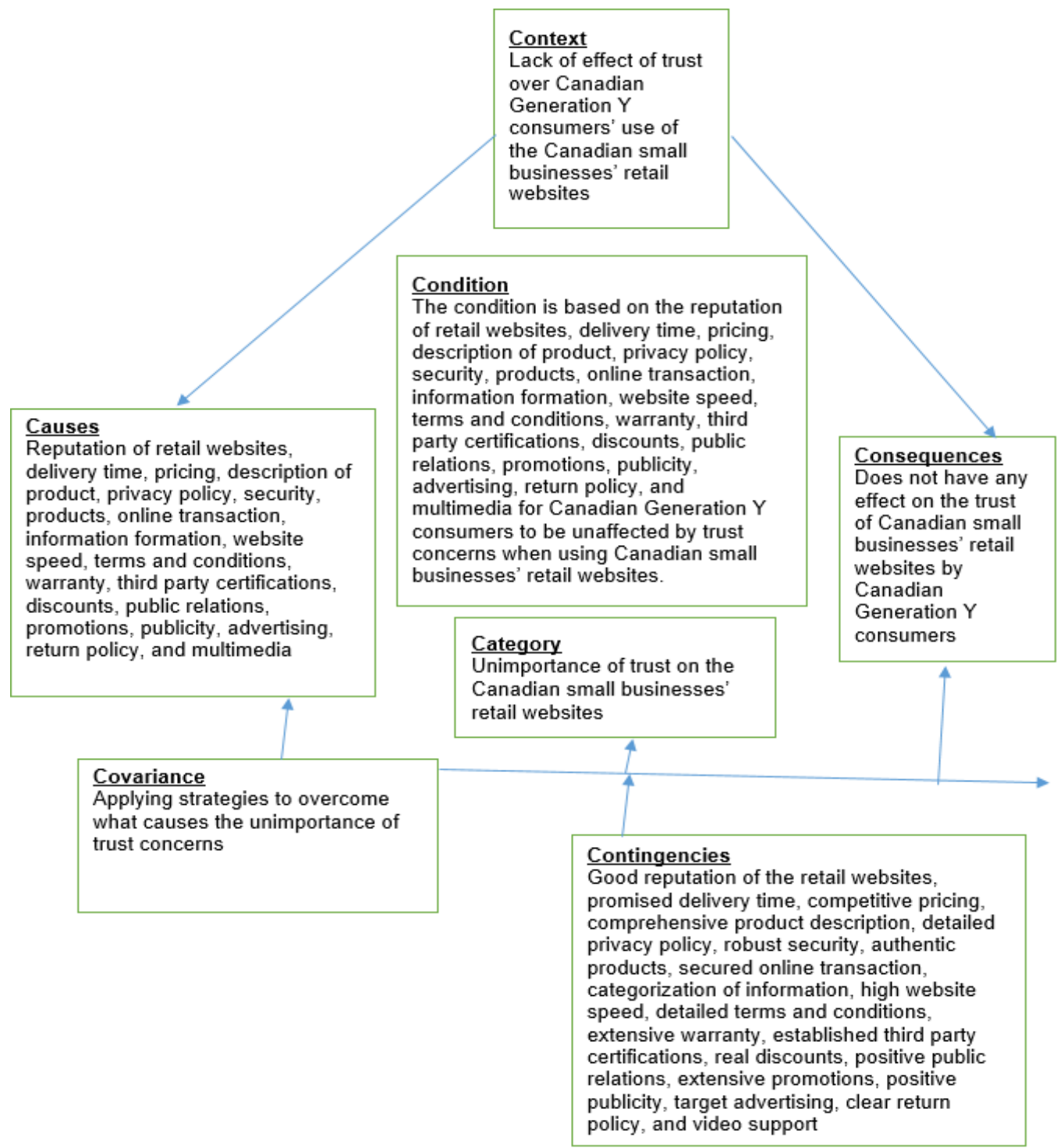

Figure 4: Trust on Retail Websites 
The context refers to the effect of trust of the Canadian small business retail websites by Canadian Generation Y consumers. The condition is the reasons Canadian Generation Y consumer are unaffected by trust for Canadian small business retail websites. The category is based on the unimportance of trust. The causes are what does not have an effect on trust for Canadian Generation Y consumers. Consequences are the effects of the causes. Covariance refers to the strategies to overcome the causes that do not affect the trust of Canadian Generation Y consumers. Contingencies are the detailed actions to overcome what causes the unimportance of trust.

\section{Context}

The context of this research is based on the lack of effect of trust over Canadian Generation $\mathrm{Y}$ consumers' use of the Canadian small business retail websites.

\section{Condition}

The condition is based on certain reasons that are required for Canadian Generation $\mathrm{Y}$ consumers to be unaffected by trust concerns when using Canadian small business retail websites.

\section{Causes}

The causes are reputation of retail websites, delivery time, pricing, description of product, privacy policy, security, products, online transaction, information formation, website speed, terms and conditions, warranty, third party certifications, discounts, public relations, promotions, publicity, advertising, return policy, and multimedia.

Reputation of Retail Websites: The reputation of retail websites can leverage the nonimportance of trust on retail websites. According to A5, "There is tremendous online retail competition. The reputation of the websites and branded products can differentiate others." $\mathrm{He}$ claims that the reputation of a retail website can offset the lack of trust of Canadian Generation Y consumers toward Canadian small business retail websites.

Delivery Time: Fast and consistent delivery time can also mitigate the unimportance of trust on retail websites. A19 explains, "I am not sure of the reliability of small retailers. Delivery can be a concern." A consumer who is new to online purchasing or wants to shop at a specific retail website for the first time can review comments from social media, blogs, and other information on the Internet or elsewhere. Consumers need to ascertain what constitutes fast delivery and review consistency of delivery time for themselves based on their needs and wants. For the same, delivery time will help curtail the importance of trust on retail websites.

Product Pricing: Competitive product pricing based on value can alleviate non-trust on retail websites. The reason the researcher uses the term product pricing based on value is with the knowledge that consumers do not necessarily purchase products simply due to the lowest price. The product quality is also a variable. For a product that is valueworth, consumers purchase the product related to the expected value based on the lowest price. The value of a product can be based on features, size, and durability, to name a few.

Description of Product: The description of a product can help leverage the non-importance of trust when purchasing on retail websites for Canadian Generation Y consumers. According to A15, "I am worried about fake goods. That is why I am buying from reputable websites." There should not be any contradiction with the actual description of the 
product that enhances the effect of not being able to touch and feel the product in the virtual environment. The description of a product should be detailed and having a video presentation can better explain and describe the product, adding reassurance.

Privacy Policy and Security: The privacy policy can help alleviate trust issues on retail websites. According to A3, "Retail websites are secured but I want to see privacy being written." According to A6, "My personal data needs to be protected. I hate websites that are slow." By establishing a privacy policy, consumers are more convinced to shop at a specific retail website. With an established privacy policy, there is no ambiguity on how consumers' personal data will be used. The clarity of the privacy policy can obtain conviction from the consumer as they will not be struggling to interpret any "grey area" of the privacy policy. When a retail website has established a privacy policy, it enables consumers who visit that retail website to mitigate the importance of trust on retail websites.

Information Organisation: Well organised information compensates for the unimportance of trust on retail websites. According to A4, "I am just an average Joe. Security can still be a concern. Information that are well organised enable users to find them easily." He mentioned that he is just an average person. The information on the retail website should be organised in a meaningful manner based on categorisation, simplicity, and clarity. Information that is cluttered and lacks organisation can create difficulty for consumers trying to find information. According to A30, "Easy search for products and services can build trust for me." By organising items into themes or product lines, consumers are facilitated to search for items on the webpages with ease. Every effort should be made by retailers to create a positive online experience. Every process that a consumer experiences should occur without any hindrance with the objective of increasing sales. With this explanation, trust can be uninfluenced on retail websites.

Retail Website Speed: Retail website speed can offset the non-effect of trust on retail websites for Generation Y consumers. A6 points out that "Trust can be developed by protecting my personal data and making sure that websites are fast to access." The uploading and downloading speed need to be fast as Canadian Generation Y consumers are rushed for time. As mentioned earlier, the basic Internet download speed is at least 50 megabytes per second and upload speed is at least 10 megabytes per second (Dobby, 2017). By any comparison, the Internet speed in Canada is one of the highest in the world for basic Internet requirements. The design of the retail website saved on certain formats can also alleviate the uploading and downloading speed for the retail website. Slow speeds may deter Canadian Generation Y consumers from visiting a retail website. Slow retail websites would not contribute to the non-influence of trust on retail websites.

Terms and Conditions: Terms and conditions can mitigate the non-importance of trust on retail websites. According to A2, "It is important that the retailer promises to deliver the term as promised. Delivery time, pricing, and products are examples. I only buy online as the last resort because I cannot feel and touch the products." For A9, "I want to see that retailers uphold their terms and conditions such as delivery, product identification, price, money back guarantee, and warranty." The terms and conditions should be clear, concise, and placed in one location, rather than being scattered all over the website. This should include a clear return policy, as this is a major concern when buying online. 
Marketing Activities: Marketing activities can mitigate the influence of trust on retail websites. A23 explains that "Many of the retail websites do not try to develop a relationship with customers to build trust." According to A12, "Most of these retailers do not create awareness on public relations. I believe in getting good deals and security." A28 elaborates that "Retailers should develop more relationship building activities such as public relations, promotions, and publicity." The public relations, promotions and publicity should be community centred as, after all, the prospective and current consumers are also part of the community.

\section{Category}

The category is called the importance of trust on the Canadian small business retail websites.

\section{Consequences}

The consequences are that they may not increase the use of the Canadian small business retail websites by Canadian Generation Y consumers.

\section{Covariance}

Covariance is based on strategies to overcome what causes the unimportance of trust concerns.

\section{Contingencies}

Contingencies are based on the good reputation of the retail websites, promised delivery time, competitive pricing, a comprehensive product description, detailed privacy policy, robust security, authentic products, secured online transaction, categorisation of information, high website speed, detailed terms and conditions, extensive warranty, established third-party certifications, real discounts, positive public relations, extensive promotions, positive publicity, target advertising, clear return policy, and video support.

\section{MAJOR FINDINGS AND DISCUSSION}

The research question of the study is explored to answer how Canadian Generation Y consumers can be enticed to increase the adoption of Canadian small business retail websites.

Based on the feedback received from the interviewees, it can be said that the respondents have mixed opinions regarding the security and privacy of Canadian small business retail websites. These businesses are small in nature and may be perceived as not having the budget to improve their security and protect the consumers' privacy. Many Canadian Young Generation are unfamiliar about the laws enacted by the Canadian Federal government and the provincial and territorial governments to protect their security and privacy. There is a need for these governments to communicate effectively through various media in order to create an awareness within the Canadian public by explaining how to mitigate online security and privacy risks. The public awareness campaigns should further explain the availability of current technologies and the enacted laws for Internet commerce that can be used by consumers and businesses to minimise such risks.

The Canadian government has started numerous initiatives to promote e-commerce by establishing various action plans (Government of Canada, 2015b). The Global Markets Action Plan was introduced to target an increase from 11,000 to 21,000 of the Canadian Small Medium Enterprises (SMEs) who are exporting to emerging economies. Under the Digital Canada 150 initiative, the Canadian government has invested $C \$ 300$ million funded by 
venture capital from digital companies through the Business Development Bank of Canada and another C $\$ 200$ million to provide SMEs with digital technology adoption.

Although the Canadian government has started different initiatives for small businesses to establish Internet commerce, there seems to be a lack of awareness among Canadian Young Generation and the public at large about these initiatives. There are hardly any awareness programmes that target the different stakeholders of the Internet commerce on any media.

Further, interviews revealed that the Canadian Young Generation prefer to see simple website designs that have large visuals, contrasting colours, large banners, standardisation, and a simple checkout. The design should be supported by themes, product information, price listing, and customer reviews. For many Canadian Generation Y consumers, unsolicited advertisements in the form of emails and pop-up advertisements and excessive advertising are annoying. Coupons are a good way to advertise as consumers can get discounts or try out the products for free. In the consumers' perspective, this form of advertising reduces their product risk. Using videos such as YouTube to advertise how a product or service can be used can enhance the customers' confidence. By integrating advertisements into an interactive game, consumers can be engaged and entertained, thereby improving the understanding of a product.

Customer loyalty programmes should be established and maintained by Canadian small businesses as long as there are mutual benefits for the customers and the small businesses. For Canadian Generation Y consumers, the benefits can come in the form of discounts and gifts for the purchase, rewards for referrals, and recognition. In order to promote customer loyalty programmes, membership fees can be waived off. For the Canadian small businesses, the benefits can come in the form of retaining existing customers and developing relationship with new ones and thereby increase their sales and profits.

\section{CONCLUSION}

It is the goal of this study to apply the UTAUT2 paradigm to a new research context: the enticement of small business websites by Canadian Young Generation. There has never been a study like this done before in this exact setting, and the findings of this study will help us gain a better understanding of the elements that encourage its adoption. A new theory may be found and important theoretical contributions can be made, according to Venkatesh, Thong, and Xu (2016), who state that applying UTAUT/UTAUT2 models to new contextual circumstances will assist to address the gaps in existing research. Additionally, personal interview data is used to support this research, which gives insight into the elements that contribute to UTAUT2.

Small company merchants in Canada should continue to focus on Canadian Young Generation since more of them will enter the workforce and take over as major consumers from the baby boomers. They are anticipated to become more prosperous in the near future, as well as to have greater discretionary and disposal earnings. However, it is possible that this may not prevent Generation Y customers from continuing to shop online because they have low levels of faith in security and privacy protection, as well as trust in small company retail websites in Canada.

Small company merchants in Canada may benefit from the depreciation of the Canadian dollar by increasing their online marketing efforts and promotions in order to grow their sales from the United States and other countries that are benefiting from higher currency exchange rates. 
Because small businesses contribute significantly to the Canadian economy and the generation of jobs, the Canadian government should become more involved in this sector by developing programs and providing subsidies to encourage small business growth and development. This means that the use of the Internet may be out of reach for many Canadian Young Generation because the PV is determined to be non-significant. In order to minimize the costs of Internet access, it is believed that increased competition will result in a reduction in prices.

This survey has revealed how Generation Y loves to attract people to use the Internet and what expectations they have of companies who sell their products online. Many insights have been gained from the ideas and opinions of the respondents and interviewees, including information on the security and privacy of transactions, the trustworthiness and aesthetics of websites, and the use of social media to advertise products by small businesses. Small retailers who offer their products online will find the tips to be of tremendous practical assistance.

A greater number of safeguards for security and privacy, as well as mechanisms for establishing trust, must be put in place in order to strengthen the confidence of Young Generation consumers in the retail websites of small Canadian firms. In Canada, internet rates remain expensive, and it is proposed that the Canadian federal Government Issue more Internet Service Provider (ISP) licenses in order to increase competition among ISPs and, as a result, bring Internet charges down. Still, small Canadian firms are rapidly and gradually expanding their sales channels to include the Internet as a part of their overall strategy.

\section{REFERENCES}

Alharbi, I. M., Zyngier, S. and Hodkinson, C. (2013). Privacy by design and customers' perceived privacy and security concerns in the success of e-commerce, Journal of Enterprise Information Management, 26(6), pp. 702-718.

Baumann, C., Elliott, G. and Hamin, H. (2011). Modelling customer loyalty in financial services: A hybrid of formative and reflective constructs, International Journal of Bank Marketing, 29(3), pp. 247-267.

Blut, M., Beatty, S. E., Evanschitzky, H. and Brock, C. (2014). The impact of service characteristics on the switching costs - Customer loyalty link, Journal of Retailing, 90(2), pp. 275-290.

Canada Post (2017). Looking to attract the Canadian millennial shopper? Get to know them first. [Online accessed, 13th June, 2018]. https://www.canadapost.ca/web/en/blogs/business/details.page?article=2017/03 /20/canadian_millennials\&cattype=business\&cat=shipping

Canadian Association of Marketing Professionals (2014). Generation huh? [Online accessed, 2nd January, 2015]. http://canadianmarketer.ca/generation-huh/

CANARIE (2015). Government of Canada renews its investment in CANARIE: \$105M for 5-year mandate. [Online accessed, 27th October, 2015]. http://www.canarie.ca/governmentof-canada-renews-its-investment-in-canarie-105m-for-5-year-mandate/

CIBC World Markets (2003). Canadian Small Business - A Growing Force, p. 2.

Clarke, R. (2013). Information security for small and medium-sized organisations, Xamax Consultancy Private Limited, January. [Online accessed, 12th October, 2015]. http://www.xamax.com.au/EC/ISInfo.pdf 
Diamantopoulos, A. (1999). Export performance measurement: Reflective versus formative indicators, International Marketing Review, 16(6), pp. 444-457.

Dimoka, A., Hong, Y. and Pavlou, P. A. (2012). On product uncertainty in online markets: Theory and evidence, MIS Quarterly, 36(2), pp. 395-426.

Djamasbi, S., Siegel, M. and Tullis, T. (2010). Generation Y, web design, and eye tracking, International Journal of Human-Computer Studies, 68(5), pp. 307-323.

Donepudi, P. K., Ahmed, A. A. A., \& Saha, S. (2020a). Emerging Market Economy (EME) and Artificial Intelligence (AI): Consequences for the Future of Jobs. PalArch's Journal of Archaeology of Egypt/ Egyptology, 17(6), 5562-5574. https://doi.org/10.5281/zenodo.5562662

Donepudi, P. K., Ahmed, A. A. A., Hossain, M. A., \& Maria, P. (2020b). Perceptions of RAIA Introduction by Employees on Employability and Work Satisfaction in the Modern Agriculture Sector. International Journal of Modern Agriculture, 9(4), 486497. https:// doi.org/10.5281/zenodo.4428205

Donepudi, P. K., Banu, M. H., Khan, W., Neogy, T. K., Asadullah, ABM., \& Ahmed, A. A. A. (2020c). Artificial Intelligence and Machine Learning in Treasury Management: A Systematic Literature Review. International Journal of Management, 11(11), 1322. https://doi.org/10.5281/zenodo.4247297

Dorotic, M., Bijmolt, T. H. A. and Verhoef, P. C. (2012). Loyalty programmes: current knowledge and research directions, International Journal of Management Reviews, 14(3), pp. 217-237.

Dowling, G. R. and Uncles, M. (1997). Do customer loyalty programs really work?, Sloan Management Review, 38(4), pp. 71-82.

Ensign, P. C. (2008). Small business considerations in Canada: The resurgence of regionalism, The Journal of Entrepreneurship, 17(1), pp. 37-47.

Fang, X., Hu, P., Chau, M., Hu, H. F., Yang, Z. and Sheng, O. (2012). A data-driven approach to measure web site navigability, Journal of Management Information Systems, 29(2), pp. 173-212.

Garner, S. (2010). Small business lessons from Generation Y, GoForth Institute, May $26^{\text {th }}$. [Online accessed, 2nd January, 2015]. http://canadianentrepreneurtraining.com/smallbusiness-lessons-from-generation-y/

Glaser, B. G. (1978). Theoretical sensitivity: Advances in the methodology of grounded theory. Sociology Press, Mill Valley, California.

Government of Canada (2015). New law to protect the personal information of Canadians online. [Online accessed, 27th October, 2015]. http://news.gc.ca/web/articleen.do?nid=988939

Government of Canada (2015a). Canada's anti-spam legislation requirements for installing computer programs. [Online accessed, 28th October, 2015]. http://www.crtc.gc.ca/eng/info_sht/A2.htm

Government of Canada (2015b). Fast encourages Canadian companies to use e-commerce to 'go global'. [Online accessed, 28th October, 2015]. http://www.international.gc.ca/media/comm/newscommuniques $/ 2015 / 07 / 20$ a.aspx?lang=eng 
Guffey, M. E., Rhodes, K. and Rogin, P. (2010). Business communication: Process and product. Third Brief Canadian Edition, Nelson Education, USA.

Innovation, Science and Economic Development Canada (2016). Key small business statistics, Government of Canada, June.

Jansen, B. J., Sobel, K. and Zhang, M. (2011). The brand effect of key phrases and advertisements in sponsored search, International Journal of Electronic Commerce, 16(1), pp. 77-106.

Jefferson, S. and Tanton, S. (2013). Valuable content marketing: How to make quality content the key to your business success, Kogan Page, pp. 150-200.

Jones, D. (2011). It's Evolution, Baby, Benefits Canada.

Khan, W., Ahmed, A. A. A., Hossain, M. S., Neogy, T. K. (2020). The Interactive Approach to Working Capital Knowledge: Survey Evidence. International Journal of Nonlinear Analysis and Applications, 11(Special Issue), 379-393. https://doi.org/10.22075/ijnaa.2020.4631

Kim, K. and Kim, J. (2011). Third-party privacy certification as on online advertising strategy: An investigation of the factors affecting the relationship between third-party certification and initial trust, Journal of Interactive Marketing, 25(3), pp. 145-158.

Lightner, N. J. and Zeng, L. (2011). What is still wrong with the World-Wide Web? An update after a decade, Journal of Intelligent Manufacturing, 22, pp. 3-15.

Manojkumar, P., Suresh, M., Ahmed, A. A. A., Panchal, H., Rajan, C. C. A., Dheepanchakkravarthy, A., Geetha, A., Gunapriya, B., Mann, S., \& Sadasivuni, K. K. (2021). A novel home automation distributed server management system using Internet of Things. International Journal of Ambient Energy, https://doi.org/10.1080/01430750.2021.1953590

Marilee, (2011). Generation Y: Challenging employers to provide balance. Who are Generation Y and do employers and managers in the non-profit sector really need to fear them?, BC Council for Families. [Online accessed, 2nd January, 2015]. http:/ / www.bccf.ca/all/resources/generation-y-challenging-employers-providebalance

McDonald, K. S. and Hite, L. M. (2008). The next generation of career success: Implications for HRD, Advances in Developing Human Resources, 10(1), pp. 86-103.

Noort, G., Voorveld, H. A. M. and Reijmersdal, E. A. (2012). Interactivity in brand web sites: Cognitive, affective, and behavioural responses explained by consumers' online flow experience, Journal of Interactive Marketing, 26(4), pp. 223-234.

Ponte, E. B., Carvajal-Trujillo, E. and Escobar-Rodriguez, T. (2015). Influence of trust and perceived value on the intention to purchase travel online: Integrating the effects of assurance on trust antecedents, Tourism Management, 47(3), pp. 286-302.

Rahman, M. M., Chowdhury, M. R. H. K., Islam, M. A., Tohfa, M. U., Kader, M. A. L., Ahmed, A. A. A., \& Donepudi, P. K. (2020). Relationship between SocioDemographic Characteristics and Job Satisfaction: Evidence from Private Bank Employees. American Journal of Trade and Policy, 7(2), 65-72. https://doi.org/10.18034/ajtp.v7i2.492

Redmond, A. (2014). The challenges facing Generation Y: A diverse set of transferable skills is mandatory for this generation, Morning Star Research Incorporated, February 28th. 
[Online Accessed, 2nd 2015]. http:/ / cawidgets.morningstar.ca/ArticleTemplate/ArticleGL.aspx?culture=enCA\&id $=637380$

Rosen, D. E. and Purinton, E. (2004). Website design: Viewing the web as a cognitive landscape, Journal of Business Research, 57(7), pp. 787-794.

Sharma, D. K., Chakravarthi, D. S., Shaikh, A. A., Ahmed, A. A. A., Jaiswal, S., Naved, M. (2021). The aspect of vast data management problem in healthcare sector and implementation of cloud computing technique. Materials Today: Proceedings. https://doi.org/10.1016/j.matpr.2021.07.388

Shaw, H. (2017). Amazon's Prime a more 'pressing threat' for Canadian retailers than its Whole Foods acquisition: BMO, Financial Post, June 26th. [Online accessed, 3rd September, 2018]. https://business.financialpost.com/news/retailmarketing/amazons-prime-a-more-pressing-threat-for-canadian-retailers-than-itswhole-foods-acquisition-bmo

Shin, J. and Sudhir, K. (2010). A customer management dilemma: When is it profitable to reward one's own customers?, Marketing Science, 29(4), pp. 671-689.

Smith, K. T. (2011). Digital marketing strategies that millennials find appealing, motivating, or just annoying, Journal of Strategic Marketing, 19(6), pp. 489-499.

Statistics Canada (2014). Retail at a glance: E-commerce sales, 2012. [Online accessed, 31st January, 2016]. http://www.statcan.gc.ca/daily-quotidien/140708/dq140708beng.htm

Swan, C. (2012). Gamification: A new way to shape behaviour, Communication World, 29(3), pp. 13-14.

Tangmanee, C. (2013). Relationships among two visual attentions and fixation duration on an ad banner: An exploration through eye-tracking on YouTube, Journal of Global Business Issues, 7(1), p1-6, 6p.

Toma, A. (2014). Marketing strategies: Small retailers against big retailers, Valahian Journal of Economic Studies, 5(1), pp. 89-94.

Turban, E., King, D., Lee, J. K., Liang, T. P. and Turban, D. C. (2015), Marketing and advertising in e-commerce, Springer International Publishing, Switzerland.

Venkatesh, V., Thong, J. Y. L. and Xu, X. (2016). Unified theory of acceptance and use of technology: A synthesis and the road ahead, Journal of the Association for Information Systems, 17(5), pp. 328-376.

Yousefi, A. and Tang, J. (2012). E-commerce: Consumer online shopping in Canada, Proceedings of the Contemporary Research on E-business Technology and Strategy Communications in Computer and Information Science, pp. 1-14.

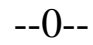

Online Archive:

https://i-proclaim.my/journals/index.php/gdeb/issue/archive 